\title{
Brief Cognitive Behavioral Therapy for Patients with Comorbid Depression and Type 2 Diabetes in an Urban Primary Care Facility: Randomized Controlled Trial
}

\author{
Nadine Mansour ${ }^{1 *}$ (D), Nargis Labib ${ }^{2}$, Mohamed Khalil $^{3}$, Shereen Esmat ${ }^{4}$ (D) \\ ${ }^{1}$ Department of Public Health and Community Medicine, Alkasr Aleini Medical School, Cairo University, Giza Health Directorate, \\ Ministry of Health and Population, Giza, Egypt; ${ }^{2}$ Department of Public Health and Community Medicine, Alkasr Aleini Medical \\ School, Cairo University, Giza, Egypt; ${ }^{3}$ Department of Psychiatry, Alkasr Aleini Medical School, Cairo University, Giza, Egypt; \\ ${ }^{4}$ Department of Public Health and Community Medicine, Alkasr Aleini Medical School, Cairo University, Giza, Egypt
}

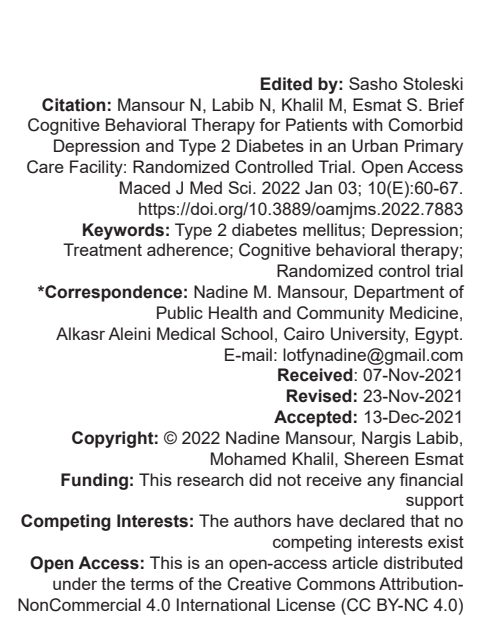

\section{Introduction}

\section{Background and Rationale}

Type 2 diabetes (T2D) is a prevalent clinical and public health problem. The World Health Organization (WHO) estimated the prevalence of diabetes among adults at $8.5 \%$ in 2014 . There was a rise in diabetes from $4.7 \%$ (108 million) in 1980 to $8.5 \%$ (422 million) in 2014 [1]. Moreover, the middle- and low-income countries are experiencing a rapid rise. According to the International Diabetes Foundation, globally, around 425 million people have diabetes, and 40 million are in the Middle East and North Africa (MENA) Region [2]. Diabetes remains a major cause of many complications such as cardiovascular diseases, renal failure, blindness, hearing impairment, stroke, and lower limb amputation. Diabetes resulted in 2.2 million deaths in 2012 and 1.6 million more in 2016. According to the $\mathrm{WHO}$, diabetes was ranked the seventh leading cause of death in 2016 [1].

\begin{abstract}
BACKGROUND: The relation between depression and diabetes is bidirectional, and both can lead to morbidity and on its use in comorbid diabetes and depression is limited and with varying results.

the randomized controlled trial at an urban primary healthcare center in Egypt. The and depression symptoms diagnosed by Beck's depression index. We assessed participants for all batteries of received four CBT sessions. Both groups received 30-min structured diabetes education and their usual diabetes (the change in depressive symptoms assessed) were analyzed using ANCOVA.

RESULTS: Both groups were matching at baseline. Post-intervention, the CBT group revealed a significant reduction index $(F[1,73]=4.27, p=0.042)$ compared to the control group. in depressive symptoms while adjusting for beck depression index $(B D I)$ pre-intervention $(F[1,74]=7.074, p=$
\end{abstract}

CONCLUSIONS: The results indicated CBT intervention was effective in improving diabetes control and depression. However, we recommend a future study to test its long-term impact.

The relation between depression and diabetes is bidirectional. T2D is a risk factor for depression, comorbid anxiety, and diabetes-specific distress [3]. Diabetes itself and the lifestyle demands impose many psychological burdens on diabetic patients [4]. On the other hand, depression increases the risk of developing T2D [3]. Studies have shown individuals with diabetes are two to three times more susceptible to developing depression than the general population. Such individuals are vulnerable to poor diet and metabolic control, and adherence to medication regimens, and consequently, decreased quality of life [5], [6], [7].

In Europe, the economic impacts of depression on the healthcare system and society were estimated at 118 billion Euros in 2004 [8]. On the other hand, Egypt's healthcare expenditure on diabetes is approximately $\$ 116$ per person. That is equivalent to $16 \%$ of its total health expenditure. The total direct and indirect costs of diabetes treatment were $\$ 74.3$ million and $\$ 11.8$ million, respectively [9], [10]. 
The psychological status of diabetic patients impacts their health behavior and clinical outcomes significantly. Psychological interventions are important tools to amending health behavior in T2D [11]. Cognitive behavioral therapy (CBT) has been an effective non-pharmacologic treatment for many mental disorders such as depression, anxiety, post-traumatic stress disorder, eating disorders, and schizophrenia [12]. The therapeutic approach promotes coping capabilities against challenging situations. It targets a change in negative patterns of cognition and associated behaviors and promotes emotional regulation [13]. Nevertheless, practitioners could only identify around only $44 \%$ of depressed diabetic patients. Such under-recognition is attributed to low diabetic outcomes [14], [15].

There is a growing body of research on the effect of psychological techniques in managing chronic diseases [16]. Despite the success of CBT in managing psychiatric comorbidities, research on its use in the treatment of chronic medical conditions such as diabetes is limited and with varying results [4]. Moreover, many studies that investigated the burden of depression in T2D were in high-income countries. In the MENA region, there is a dearth of research on this topic. In Egypt, there are no published data on the effect of psychological interventions among patients with diabetes.

Despite the significant relationship between depression and T2D, few published studies investigated the effect of CBT in improving disease outcomes among diabetic patients. To address such shortcomings, we conducted this randomized controlled trial (RCT) to test the hypothesis that adults with $\mathrm{T} 2 \mathrm{D}$ receiving $\mathrm{CBT}$ will demonstrate better glycemic control versus the control group. Moreover, they will show significantly lower levels of depressive symptoms post-intervention.

\section{Methods}

\section{Study design and procedure}

We implemented this parallel RCT at Al-Agouza Family Medicine Center (AFMC) in Giza, Egypt, from February 2019 to March 2020. The trial was registered at clinicaltrials.gov (NCT04214600). The Elkader Eleni medical school, Cairo University research ethics committee approved this trial (D- 49-2019).

\section{Eligibility criteria}

Eligible patients were within the age range of 35-80 years; ambulatory; able to give informed consent; and able to obtain reliable information.
Patients were included if they met the American Diabetes Association criteria for T2D (Glycated hemoglobin $[\mathrm{HbA} 1 \mathrm{c}] \geq 6.5 \%$; Fasting Plasma Glucose [FPG] $\geq 126 \mathrm{mg} / \mathrm{dL} ;$ and 2-h plasma glucose [2-h PG] $\geq 200 \mathrm{mg} / \mathrm{dL}$ ) with diagnosis confirmed by the participants' medical clinician [17] and if they score 11-30 based on beck depression index (BDI) (Mild mood disturbance to Moderate depression) [18]

Participants were excluded if they had type I diabetes and psychiatric disorders other than depression or personality disorders including schizophrenia; bipolar disorder; and substance or alcohol abuse identified using Structured Clinical Interview for DSM-IV (SCID-5) [19]. Depressed patients on treatment for depression were not included. Suicidal patients and those diagnosed with major depressive disorder were referred to a psychiatrist.

\section{Sample size}

A sample size of 80 participants (40 participants in each group) was sufficient to detect a group difference of 0.65 based on expected differences in $\mathrm{HbA} 1 \mathrm{c}$ levels of the comparison groups in the intent-to-treat (ITT) sample with a power of $80 \%$ and $5 \%$ significance level [20]. We recruited 50 participants per group to allow for an expected drop out of 15-20\%. Accordingly, we recruited a total sample of 100 randomized participants entering the 3-month trial.

\section{Pre-intervention phase}

We recruited patients over nine months through three primary mechanisms: (1) screening patients' medical records by the onsite nurse; (2) diabetic outpatients attending the AFMC clinic; and (3) the "100 million Healthy lives" national campaign.

Subsequently, the study nurse contacted the potential subjects via a telephone call. We assessed eligible participants for the various battery of instruments (demographic; diabetes mellitus [DM] history and behavior; depression, compliance to treatment, and other comorbid psychiatric conditions).

We randomly assigned patients to treatment and control groups using a simple randomization method at a 1:1 ratio. A computer-generated randomization list that included the patient's identification number was used to identify all participants' data collected throughout the study period.

The number of visits was equal for both groups to control for possible bias in the intervention. Each group option was placed in an opaque sealed envelope by a nurse at the AFMC independent from the study. Blinding of patients and all members of the research team was carried out throughout the trial. However, blinding the researcher conducting the CBT procedure was not possible. 


\section{Intervention and post-intervention phases}

All eligible patients attended a 30-40 min structured diabetes education session delivered by a trained educator. The session was an update to ensure adequate diabetes knowledge in all trial participants. It covered the pathophysiology of DM; early diabetes symptoms; risk and predisposing factors; recognition of diabetes complications; self-care including diabetesrelevant behavior (e.g., nutrition, physical activity, foot care); and monitoring and treatment of diabetes.

The intervention group received four CBT sessions every other week for 2 months. Each CBT session [21] was for 30-45 delivered during patients' typical follow-up visits. The control was a similar number as a follow-up for DM. The visits were on one to one basis. To qualify, the researcher (NM) conducting the CBT sessions had undergone systematic training by a psychiatrist (MK) and carried out the procedure under his supervision.

During the sessions, each participant worked with the researcher to (1) Identify thoughts and determine their effect on actions and feelings; (2) Challenge and analyze each thought to work out if it has been realistic or unhelpful; and (3) Find out an alternative, balanced thought. The physician helped the patients' change unhelpful thinking and behaviors by teaching them new skills they could apply daily.

Three months later, we assessed all participants for depression using BDI and repeated all lab tests including, FPS, 2-h PG, and HbA1c.

\section{Statistical methods}

The analysis was conducted according to the Consolidated Standards of Reporting Trials guideline. Precoded data were entered on Microsoft office excel program for windows, 2010. Data were transferred to the Statistical Package for Social Science Version 21 (V 21).

Quantitative variables were examined for normality distribution using the Shapiro-Wilks's test ( $p$ $>0.05$ ) [22], [23]. Results of $p<0.05$ were considered significant indicating non-normal distribution. A parametric Levene's test was used to verify the equality of variances in the samples (homogeneity of variance) $(p>0.05)$ [24], [25].

Exploratory $p$-values of the student twotailed independent t-tests and Chi-square test between study groups were used for the baseline quantitative and qualitative variables, respectively. We used 2-sided p-values with an alpha $\leq 0.05$ level of significance were reported to three decimal places, for example, $p<0.001$.

Analyses employed the ITT principle. In which patients who dropped out prematurely; were non-compliant; or had taken the wrong intervention, were included in the primary analysis within the respective treatment group they were assigned to at randomization [26].

Two sets of analyses were conducted corresponding to the study outcomes' endpoints: (1) the CBT group demonstrated improvement of $\mathrm{HbA} 1 \mathrm{c}$ level at the end of the sessions and (2) they demonstrated improvement of depression score on BDI versus the control.

We used the analysis of covariance (ANCOVA) [27], the General Linear Modeling approach to compare the study groups for:

1. The primary outcome in which the postintervention $\mathrm{HbA} 1 \mathrm{c}$ was the dependent variable while controlling for baseline $\mathrm{Hb} \mathrm{A} 1 \mathrm{C}$. Further analysis was conducted where the postintervention $\mathrm{HbA} 1 \mathrm{c}$ as a dependent variable whilst controlling for the baseline BDI scores and body mass index (BMI) as independent variables

2. Analysis for the secondary outcome in which the BDI score post-intervention was the dependent variable and baseline BDI score as a covariate was used. Another ANCOVA was conducted where the post-intervention BDI was the dependent variable while controlling for the effect of $\mathrm{HbA} 1 \mathrm{c}$ and $\mathrm{BMI}$ before the intervention. For that, the assumption of homogeneity of regression slope was examined by testing the interaction effect of the independent variable and the covariate.

Furthermore, Pearson correlation was used to examine the relationships between $\mathrm{HbA1c}$ value post-intervention and baseline BDI-scores. Appropriate methods were employed on an individual basis for the missing values and variables normalization. The primary analyses for "HbA1c" and the "BDI scores" were repeated after employing the last observation carried forward method. The logarithm, base 10 (Log 10) was used for the non-normal variable "FBG" [28]. If outliers were apparent to bias the analysis, they were set to missing.

\section{Results}

\section{Participants' flow diagram and baseline}

\section{data}

Of the 394 patients we screened, 100 met the inclusion criteria and completed the baseline assessment. Subsequently, they were randomized to either the CBT group $(n=50)$ or the control $(n=50)$ and included in the ITT analysis. Regarding the attended sessions, for the control group, $24 \%$ received four; $22 \%$ had three; $54 \%$ had two or less. Of the participant allocated to the intervention group, $22 \%$ received the 
four CBT sessions; $38 \%$ had three, and $40 \%$ received two or fewer. At the post-intervention assessment, $72 \%$ of the control provided complete data and $82 \%$ of the CBT group (Figure 1). There were no study-related adverse events.

The CBT and control were matching for sociodemographic characteristics with no significant statistical difference between the study groups shown in Table 1. Around three fourth $(74 \%)$ of the participants were $>45-54$ years of age for both groups. The majority of the study participants were married $(62 \%)$, female $(69 \%)$, and illiterate $42 \%$. More than half the patients $(60 \%)$ were unemployed, and around half of the participants (48\%) were housewives.
There was no statistical difference of significance between both groups before intervention as regards the BDI scores $(p=0.129)$. Both the anthropometric measures (weight, height, BMI, and waist circumference) and laboratory tests including FPG (mg/dl); 2 h PG (mg/dl); and HbA1c (\%) showed p > 0.05 (Table 2). The age of onset of diabetes was statistically insignificant too (The control: $M=46.62, S D=10.98$ vs. the intervention: $M=46.06, S D=9.65), t(98)=0.27, p=$ 0.787 , ns). A Mann-Whitney test indicated the duration of diabetes was greater for the control group $(\mathrm{Mdn}=8.00)$ than for the CBT (Mdn = 10.50), $U=1236, p=0.923$.

The majority of the studied participants $(41 \%)$ had one comorbid condition (44\% for control and $38 \%$

\section{Einrolliment}

Assessed for eligibility $(\mathrm{n}=394)$
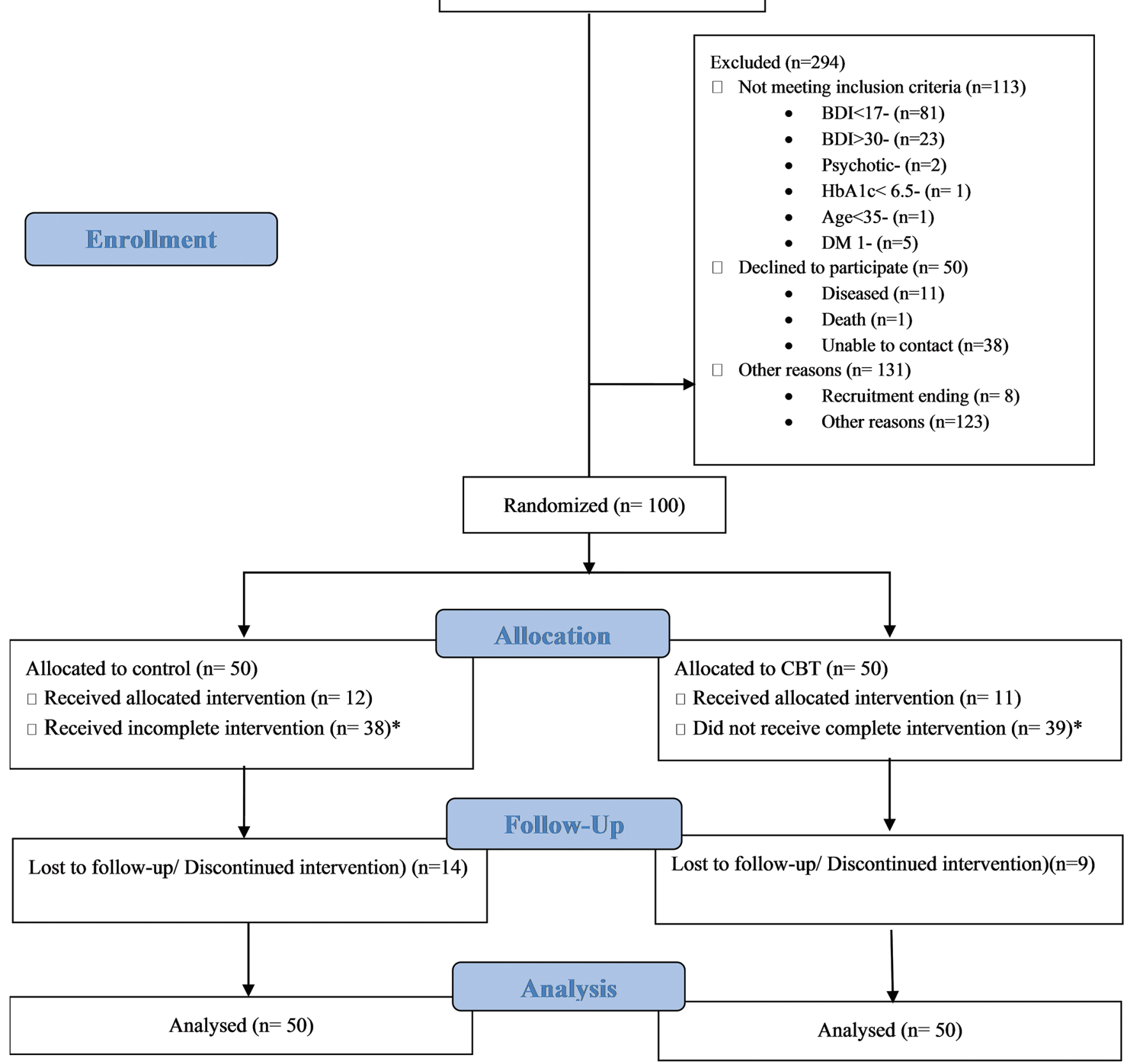

Figure 1: Consolidated standards of reporting trials flow diagram of participants. *Attended $<4$ sessions 
Table 1: Distribution of the study groups according to their sociodemographic characteristics, $n=100$

\begin{tabular}{|c|c|c|c|}
\hline Variables & Control $(n=50) \%$ & CBT $(n=50) \%$ & $p$-value \\
\hline \multicolumn{4}{|l|}{ Age } \\
\hline $35-44$ & 10 & 24 & \multirow[t]{4}{*}{0.220} \\
\hline $45-54$ & 38 & 36 & \\
\hline $55-64$ & 22 & 12 & \\
\hline$\geq 65$ & 30 & 28 & \\
\hline \multicolumn{4}{|l|}{ Sex } \\
\hline Male & 30 & 32 & \multirow[t]{2}{*}{0.829} \\
\hline Female & 70 & 68 & \\
\hline \multicolumn{3}{|l|}{ Marital status } & \multirow[t]{5}{*}{0.355} \\
\hline Single & 0 & 4 & \\
\hline Married & 68 & 56 & \\
\hline Divorced & 12 & 12 & \\
\hline Widowed & 20 & 28 & \\
\hline \multicolumn{4}{|l|}{ Education level } \\
\hline Illiterate & 36 & 48 & \multirow[t]{6}{*}{0.311} \\
\hline Read and write & 14 & 8 & \\
\hline Primary & 10 & 8 & \\
\hline Preparatory & 4 & 12 & \\
\hline Secondary & 8 & 2 & \\
\hline University & 28 & 22 & \\
\hline \multicolumn{4}{|l|}{ Employment status } \\
\hline Full time & 26 & 30 & \multirow[t]{6}{*}{0.874} \\
\hline Part time & 2 & 6 & \\
\hline Per diem & 8 & 8 & \\
\hline Unemployed & 8 & 6 & \\
\hline Retired & 4 & 6 & \\
\hline Housewife & 52 & 44 & \\
\hline \multicolumn{4}{|l|}{ Employment group } \\
\hline No work & 64 & 56 & \multirow[t]{6}{*}{0.717} \\
\hline Unskilled worker & 18 & 28 & \\
\hline Manual skilled worker & 4 & 2 & \\
\hline Managerial work & 6 & 4 & \\
\hline Semi-professional (clerk) & 0 & 2 & \\
\hline Professional & 8 & 8 & \\
\hline
\end{tabular}

for CBT). Only a few had four to five comorbidities. The most common was hypertension in $58 \%$ of the control group and $48 \%$ of the CBT. Around $30 \%$ of the patients experienced one or two side effects of T2D (control $24 \%$ and CBT 38\%) and (control 30\% and CBT 36\%) respectively. The commonly experienced side effect was tingling/numbness for both groups (79\% for control and $86 \%$ for CBT).

Table 2: Comparison between study groups according to their assessment of depressive symptoms using the BDI scoring and baseline laboratory tests, $n=100$

\begin{tabular}{llll}
\hline Baseline assessment & Control $(\mathrm{n}=50)$ Mean \pm SD & CBT $(\mathrm{n}=50)$ Mean \pm SD & p-value \\
\hline FPG $(\mathrm{mg} / \mathrm{dl})$ & $198.46 \pm 55.11$ & $209.26 \pm 62$ & 0.393 \\
2h PG $(\mathrm{mg} / \mathrm{dl})$ & $278.58 \pm 74.63$ & $281.10 \pm 78.12$ & 0.869 \\
HbA1c $(\%)$ & $9.60 \pm 1.71$ & $9.44 \pm 1.72$ & 0.626 \\
BDI before intervention & $19 \pm 6.24$ & $21 \pm 6.16$ & 0.129 \\
\hline FPG: Fasting plasma glucose; 2-h PG: 2-h plasma glucose; HbA1c: Glycated hemoglobin. CBT: Cognitive
\end{tabular}

FPG: Fasting plasma glucose; 2-h PG: 2-h plasma glucose; HbA1c: Glycated hemoglobin. CBT: Cognitive behavioral therapy, $\mathrm{BDI}$ : Beck depression index

\section{Post-intervention outcomes for diabetes control and depression}

We ensured the ANCOVA assumption for the outcomes was fulfilled using: (1) Shapiro-Wilk test was $p>0.05$; (2) Visually inspecting the histogram, $Q-Q$ plots, and box plots for normal distribution at the level of each group for $\mathrm{BDI}$ score and $\mathrm{HbA1c}$ post-intervention as independent variables and the baseline BDI scores, HbA1c, and BMI [29]; (3) A parametric Levene's test was $p>0.05$, indicating homogeneity of variance between groups; and (4) The homogeneity of regression of the BDI score and $\mathrm{HbA} 1 \mathrm{c}$ post-intervention was statistically insignificant (>0.05).

The findings from ANCOVA using the General Linear Modeling approach after adjustment for baseline $\mathrm{HbA} 1 \mathrm{c}$ as a covariate. $\mathrm{HbA} 1 \mathrm{c}$ after the intervention was statistically insignificant for both groups $(F[1,74]=2.82$, $p=0.097$ ). We conducted further analysis to compare the effect of the CBT program while controlling for the baseline BDI scores and BMI. There was a significant difference in the mean $\mathrm{HbA} 1 \mathrm{c}(\mathrm{F}[1,73]=4.27, \mathrm{p}=$ 0.042 ) between the study groups shown in Table 3.

Table 3: Distribution of study groups according to assessment of depression after intervention, $n=77$

\begin{tabular}{llcc}
\hline $\begin{array}{l}\text { Post } \\
\text { intervention }\end{array}$ & Control $(n=36)$ & CBT $(n=41)$ & p-value \\
\hline $\begin{array}{l}\text { BDI } \\
\text { Unadjusted }\end{array}$ & $15.89(8.12)$ & $12.78(7.78)$ & 0.091 \\
$\begin{array}{l}\text { Adjusted } \\
\text { HbA1c }\end{array}$ & $16.49(1.16)$ & $12.25(1.09)$ & 0.010 \\
Unadjusted & $8.38(1.60$ & $7.82(1.47)$ & 0.070 \\
Adjusted & $8.42(0.25)$ & $7.70(0.23)$ & 0.042 \\
\hline $\begin{array}{l}\text { Standard deviations for unadjusted means and standard errors for adjusted means. CBT: Cognitive } \\
\text { behavioral therapy, HbA1c: Glycated hemoglobin, BDI: Beck depression index. }\end{array}$
\end{tabular}

There was a significant difference in BDI after the intervention $(F[1,74]=7.074, p=0.010)$ between the groups while adjusting for BDI before intervention with a CBT effect size of $8.7 \%$. The CBT group had significantly lower BDI scores for the adjusted mean shown in Table 3. We performed another one-way ANCOVA to compare the effect of the CBT program on patients' depression. There was no significant difference between the CBT and control groups after controlling for $\mathrm{HbA} 1 \mathrm{C}$ and $\mathrm{BMI}$ before the intervention $(F[1,73]=3.17, p=0.079)$.

\section{Discussion}

There was an increase in the number of studies evaluating the effect of CBT in controlling depression. Nevertheless, its impact on both psychological outcomes and glycemic control at the same time remains inconclusive [11], [30]. To the best of our knowledge, this trial is the first in Egypt. It assessed the efficacy of the CBT program in the treatment of depression in diabetic patients. At the end of intervention after 3 months, the CBT group showed a significant reduction in the glycemic index monitored by $\mathrm{HbA} 1 \mathrm{c}$ and lower depression scores measured by BDI (Table 3).

Because the effects of diabetes are known to improve with lifestyle modification, it is a good choice for a CBT-based intervention. CBT for DM helps identify barriers and challenges individuals might face and explore what they need to overcome them. Diabetic patients could enormously benefit from the one-onone support and repeated reinforcement provided by the intervention. CBT has been an effective treatment in improving depression. People with diabetes often have co-morbid depression, which can exacerbate their health condition. Therefore, CBT benefits could be ever more than merely treating depression. 


\section{Outcome measures}

Depression is associated with a decrease in diabetes control; poor adherence to medication and diet regimens; and a reduction in physical activities [31]. The study indicated the CBT intervention was effective in controlling T2D. Research has shown contradictory results. More studies have indicated CBT was effective in controlling T2D with coexisting depression [32], [33], [34].

A meta-analysis of CBT studies indicated the program was effective in reducing short to mediumterm blood glucose levels. However, its long-term effect was insignificant [4]. Contrary, Andreae et al. tested the impact of CBT on behavior, quality of life, chronic pain, and diabetes of 195 diabetic participants. The study indicated statistically insignificant changes in $\mathrm{HbA1c}$ between the control and intervention groups [35].

Regarding depression, the CBT group had significantly lower BDI scores after we adjusted for the covariates relative to the control. That suggested the intervention program had significantly improved patients' depressive symptoms. In that many meta-analyses and RCTs had reported similar results [36], [37], [38], [39].

\section{CBT intervention}

CBT is an evidence-based psychiatric approach. Possible benefits of the program include reduced depressive, distress, and anxiety symptoms. Participants had the opportunity to learn more about their disease and have their concerns addressed. They learned how to adopt new techniques in managing both life and disease stressors. Thus, they had better control over their diabetes. The program involved a multidisciplinary healthcare approach to manage patients' medical and psychological illnesses and individualized treatment regimens.

Mental health and primary care are intricately linked, making it necessary to address them in chorus. Because the CBT program is both simple and inexpensive, it could fit very well in the Primary Healthcare $(\mathrm{PHC})$ settings in developing countries. The cost of a similar intervention or provision for CBT would be worth the investment. The notion "treatment of depression must go hand in hand with the management of diabetes." is gradually gaining general acceptance. Further, we expect the intervention would change the healthcare systems.

\section{Strengths and limitations}

The study results support the prevention care model and the implementation of CBT in the preventive health sector. The trial is the first in Egypt. We recommend that managers and healthcare policymakers consider our results when developing interventions to improve the utilization of PHC centers. The Ministry of Health should enact policies and increase funding towards implementing psychiatric intervention at the $\mathrm{PHC}$ facilities. It should increase the availability of services to all Egyptians. Moreover, improve the quality and accessibility of the service to those in rural areas who have low access to healthcare facilities and suffer a high burden of non-communicable diseases. It should expand eligible activities to help recruit and retain skilled healthcare workers in the preventive sector.

We conducted this study in a single urban $\mathrm{PHC}$ facility, which may hinder the generalizability. Moreover, we did not examine the positive effect of CBT for longterm sustainability. In this, more research is required to extend the finding to other rural and urban healthcare settings. Further, to confirm the clinical importance of this intervention in the management of diabetes as a chronic condition.

Some challenges experienced include the unavailability of $\mathrm{HbA} 1 \mathrm{c}$ preparation kits. Thus, laboratory technicians had to withdraw the blood samples and perform the test in coordination with an external clinical laboratory. Some patients performed the tests at their convenience.

Although the CBT sessions have been held during regular clinic hours and at participants' convenience, retention remained a challenge to the research team. Hence, once a patient was enrolled in the trial, the team made every possible effort to follow them throughout the study period by; (1) helping the patient set diabetes-specific goals in the first session and revising these goals in each visit to maintain their interest; (2) contacting the patient to remind him/er of upcoming appointments; and (3) providing periodic feedback for each patient about his/er condition.

Since the study researcher managed patients in both the CBT and control groups, spillover of the intervention was possible. Blinding in this study was one-sided to both the data analyst and participants. However, blinding the researcher conducting the CBT intervention was not possible. Nevertheless, statistically significant improvements of the magnitude reported in this study demonstrate the potential positive effects of CBT on glycemic control and psychological outcomes.

\section{Conclusions}

The study shows the CBT intervention can improve patients' control over diabetes and depressive mood. We hope the study could significantly improve the knowledge regarding diabetes management. The CBT program is both inexpensive and easily accessible. It can fit very well in the primary care setting in developing countries. The CBT implementation could be extended further to test its impact on other chronic diseases such as hypertension, obesity, and cardiovascular disorders. 
Therein, more studies would be required to determine its applicability and suitability for such patients.

Future studies could focus on extending the implementation of the CBT program to further test its effectiveness in a more diverse population in different geographic and medical settings. That would require larger-scale research. CBT is unsustainable for a lifetime and requires a manner of transition after the intensive intervention. A goal of a subsequent study could be to examine sustainable lifestyle change and establish long-term follow-up.

\section{References}

1. Zhou B, Lu Y, Hajifathalian K, Bentham J, Di Cesare M, Danaei $G$, et al. Worldwide trends in diabetes since 1980: A pooled analysis of 751 population-based studies with 4.4 million participants. Lancet. 2016;387(10027):1513-30. https:// doi.org/10.1016/S0140-6736(16)00618-8

PMid:27061677

2. Guariguata L, Whiting DR, Hambleton I, Beagley J, LinnenkampU, Shaw JE. Global estimates of diabetes prevalence for 2013 and projections for 2035. Diabetes Res Clin Pract. 2014;103(2):13749. https://doi.org/10.1016/j.diabres.2013.11.002 PMid:24630390

3. Smith KJ, Béland M, Clyde M, Gariépy G, Pagé V, Badawi G, et al. Association of diabetes with anxiety: A systematic review and meta-analysis. J Psychosom Res. 2013;74(2):89-99. https://doi.org/10.1016/j.jpsychores.2012.11.013 PMid:23332522

4. Uchendu $\mathrm{C}$, Blake $\mathrm{H}$. Effectiveness of cognitive-behavioural therapy on glycaemic control and psychological outcomes in adults with diabetes mellitus: A systematic review and meta-analysis of randomized controlled trials. Diabetic Med. 2017;34(3):328-39. https://doi.org/10.1111/dme.13195 PMid:27472405

5. Balhara YP. Diabetes and psychiatric disorders Indian J Endocrinol Metab. 2011;15(4):274. https://doi. org/10.4103/2230-8210.85579

PMid:22028998

6. Ducat L, Philipson LH, Anderson BJ. The mental health comorbidities of diabetes. JAMA. 2014;312(7):691-2. https://doi. org/10.1001/jama.2014.8040

PMid:25010529

7. Bădescu SV, Tătaru C, Kobylinska L, Georgescu EL, Zahiu DM, Zăgrean $\mathrm{AM}$, et al. The association between diabetes mellitus and depression. J Med Life. 2016;9(2):120. PMid:27453739

8. Sobocki P, Jönsson B, Angst J, Rehnberg C. Cost of depression in Europe. J Mental Health Policy Econ. 2006;9(2):87-98. PMid: 17007486

9. Arab M. Diabetes mellitus in Egypt. World Health Stat Quart. 1992;45(4):334-7.

10. Sherif S, Sumpio BE. Economic development and diabetes prevalence in MENA countries: Egypt and Saudi Arabia comparison. World J Diabetes. 2015;6(2):304. https://doi. org/10.4239/wjd.v6.i2.304

PMid:25789111

11. Huffman JC, DuBois CM, Millstein RA, Celano CM, Wexler D.
Positive psychological interventions for patients with type 2 diabetes: Rationale, theoretical model, and intervention development. J Diabetes Res. 2015;2015:428349. https://doi. org/10.1155/2015/428349

PMid:26064980

12. Butler AC, Chapman JE, Forman EM, Beck AT. The empirical status of cognitive-behavioral therapy: A review of metaanalyses. Clin Psychol Rev. 2006;26(1):17-31. https://doi. org/10.1016/j.cpr.2005.07.003

PMid:16199119

13. Beck AT. Cognitive therapy: Nature and relation to behavior therapy-republished article. Behav Ther. 2016;47(6):776-84 https://doi.org/10.1016/j.beth.2016.11.003

PMid:27993332

14. Sorkin $\mathrm{DH}$, Nguyen $\mathrm{H}$, Ngo-Metzger $\mathrm{Q}$. Assessing the mental health needs and barriers to care among a diverse sample of Asian American older adults. J Gen Intern Med. 2011;26(6):595602. https://doi.org/10.1007/s11606-010-1612-6 PMid:21321793

15. Poulsen KM, Pachana NA, McDermott BM. Health professionals detection of depression and anxiety in their patients with diabetes: The influence of patient, illness and psychological factors. J Health Psychol. 2016;21(8):1566-75. https://doi. org/10.1177/1359105314559618 PMid:25512198

16. Gratzer D, Khalid-Khan F. Internet-delivered cognitive behavioural therapy in the treatment of psychiatric illness. CMAJ. 2016;188(4):263-72. https://doi.org/10.1503/cmaj.150007 PMid:26527829

17. Cefalu WT, Berg EG, Saraco M, Petersen MP, Uelmen S, Robinson S. 2. Classification and diagnosis of diabetes: Standards of medical care in diabetes-2019. Diabetes Care. 2019;42:S13-28. https://doi.org/10.2337/dc19-S002 PMid:30559228

18. Beck AT, Steer RA, Brown GK. Beck Depression Inventory (BDI-II). United Kingdom: Pearson; 1996.

19. First M, Spitzer R, Gibbon M, Williams JB, Benjamin L. Structured Clinical Interview for DSM-IV Axis 1 Disorders-patient Edition (SCID-I/P). New York: New York State Psychiatric Institute: Biometrics Research Department; 1996.

20. Newby J, Robins L, Wilhelm K, Smith J, Fletcher T, Gillis I, et al. Web-based cognitive behavior therapy for depression in people with diabetes mellitus: A randomized controlled trial. J Med Internet Res. 2017;19(5):e157. https://doi.org/10.2196/ jmir.7274

PMid:28506956

21. Safren S, Gonzalez J, Soroudi N. Coping with Chronic Illness: A Cognitive-behavioral Approach for Adherence and Depression Therapist Guide. Oxford: Oxford University Press; 2007.

22. Shapiro SS, Wilk MB. An analysis of variance test for normality (complete samples). Biometrika. 1965;52(3-4):591-611.

23. Razali NM, Wah YB. Power comparisons of shapiro-wilk, kolmogorov-smirnov, lilliefors and anderson-darling tests. J Statist Modeling Anal. 2011;2(1):21-33.

24. Nordstokke DW, Zumbo BD. A new nonparametric Levene test for equal variances. Psicológica. 2010;31(2):401-30.

25. Nordstokke DW, Zumbo BD, Cairns SL, Saklofske DH. The operating characteristics of the nonparametric Levene test for equal variances with assessment and evaluation data. Pract Assess Res Eval. 2011;16(1):5.

26. Gupta SK. Intention-to-treat concept: A review. Perspect Clin Res. 2011;2(3):109. https://doi.org/10.4103/2229-3485.83221 PMid:21897887

27. Barrett TJ. Computations using analysis of covariance. 
Interdiscip Rev. 2011;3(3):260-8.

28. Keene ON. The log transformation is special. Stat Med. 1995;14(8):811-9.

29. Doane DP, Seward LE. Measuring skewness: A forgotten statistic? J Stat Educ. 2011;19(2):1-18.

30. Tovote KA, Schroevers MJ, Snippe E, Emmelkamp PM, Links TP, Sanderman R, et al. What works best for whom? Cognitive Behavior Therapy and Mindfulness-Based Cognitive Therapy for depressive symptoms in patients with diabetes. PLoS One. 2017;12(6):e0179941. https://doi.org/10.1371/ journal.pone. 0179941 PMid:28662208

31. Lustman PJ, Clouse RE. Depression in diabetic patients: The relationship between mood and glycemic control. J Diabetes Complicat. 2005;19(2):113-22. https://doi.org/10.1016/j. jdiacomp.2004.01.002 PMid:15745842

32. Seyed-Reza A, Norzarina MZ, Kimura LW. The benefits of cognitive behavioral therapy (CBT) on diabetes distress and glycemic control in Type 2 diabetes. Malaysian J Psychiatry. 2016;24(2):9-15.

33. Coccaro EF, Busby AK, Potts TM, Philipson LH, Drossos T. 1120-P: Emotion-focused CBT reduces $\mathrm{HbA1c}$ levels in patients with T2D. Diabetes 2019;68(1):1120.

34. Xu C, Dong Z, Zhang P, Chang G, Xiang Q, Zhang M, et al. Effect of group cognitive behavioural therapy on psychological stress and blood glucose in people with type 2 diabetes mellitus: A community-based cluster randomized controlled trial in China. Diabetic Med. 2021;38(2):e14491. https://doi. org/10.1111/dme.14491

PMid:33296541

35. Andreae SJ, Andreae LJ, Richman JS, Cherrington AL, Safford MM. Peer-delivered cognitive behavioral training to improve functioning in patients with diabetes: A clusterrandomized trial. Ann Fam Med. 2020;18(1):15-23. https://doi. org/10.1370/afm.2469

PMid:31937528

36. Hermanns N, Schmitt A, Gahr A, Herder C, Nowotny B, Roden M, Ohmann $\mathrm{C}$, et al. The effect of a diabetes-specific cognitive behavioral treatment program (DIAMOS) for patients with diabetes and subclinical depression: Results of a randomized controlled trial. Diabetes Care. 2015;38(4):551-60. https://doi. org/10.2337/dc14-1416

PMid:25605812

37. SchmittA, Reimer A, Ehrmann D, Kulzer B, Haak T, Hermanns N. Reduction of depressive symptoms predicts improved glycaemic control: Secondary results from the DIAMOS study. J Diabetes Complications. 2017;31(11):1608-13. https://doi.org/10.1016/j. jdiacomp.2017.08.004 PMid:28865713

38. Wang ZD, Xia YF, Zhao Y, Chen LM. Cognitive behavioural therapy on improving the depression symptoms in patients with diabetes: A meta-analysis of randomized control trials. Biosci Rep. 2017;37(2):0557. https://doi.org/10.1042/BSR20160557 PMid:28183873

39. Young EE, Unachukwu CN. Psychosocial aspects of diabetes mellitus. Afr J Diabetes Med. 2012;20(1):521. 